\title{
Drug Resistance of Mycobacterium tuberculosis Complex in a Rural Setting, Angola
}

\author{
Ariadna Rando-Segura, ${ }^{1}$ María Luisa Aznar, ${ }^{1}$ \\ María Milagros Moreno, Mateu Espasa, \\ Elena Sulleiro, Cristina Bocanegra, Eva Gil, \\ Arlete N.E. Eugénio, Carlos Escartin, \\ Adriano Zacarias, Josep Vegue, \\ Domingos Katimba, María Carmen Vivas, \\ Estevao Gabriel, María Concepción Marina, \\ Jacobo Mendioroz, María Teresa López, \\ Tomas Pumarola, Israel Molina, \\ María Teresa Tórtola
}

We found high prevalence rates of multidrug-resistant tuberculosis among retreatment patients $(71.1 \%)$ and persons with new cases (8.0\%) in Angola. These findings are of concern but should be interpreted with caution. A national drugresistance survey is urgently needed to determine the actual prevalence of multidrug-resistant tuberculosis in Angola.

\begin{abstract}
ngola is among the 30 countries with the highest inAcidence of tuberculosis (TB) and multidrug-resistant (MDR) TB worldwide (1). However, drug-resistance prevalence is unknown in the absence of a national survey or laboratory drug-resistance surveillance systems (1). The objectives of our study were to determine the proportion of TB drug resistance in isolates from pulmonary TB patients and describe molecular mechanisms accounting for drug resistance in these isolates.
\end{abstract}

\section{The Study}

We conducted a survey during April 2014-July 2015 at the Nossa Senhora da Paz Hospital (HNSP), a reference center for the diagnosis and treatment of TB in the town of Cubal, Benguela Province, Angola. Patients $>16$ years of age with a diagnosis of pulmonary TB (i.e., patients with clinical symptoms and a positive smear result) and those infected with HIV who had suggestive clinical signs of pulmonary

Author affiliations: Vall d'Hebron University Hospital, PROSICS Barcelona, Universitat Autònoma de Barcelona, Barcelona, Spain (A. Rando-Segura, M.L. Aznar, M. Espasa, E. Sulleiro,

C. Bocanegra, E. Gil, C. Escartin, J. Vegue, M.C. Vivas,

M.C. Marina, J. Mendioroz, T. Pumarola, I. Molina, M.T. Tórtola); Hospital Nossa Senhora da Paz, Cubal, Angola (M.L. Aznar, M.M. Moreno, C. Bocanegra, E. Gil, A.N.E. Eugénio, A. Zacarias, D. Katimba, E. Gabriel, M.T. López)

DOI: https://doi.org/10.3201/eid2403.171562
TB but negative sputum samples for acid-fast bacilli were eligible for enrollment in the study. We collected data on age, sex, HIV status, and any previous TB treatment.

Before the start of treatment, we collected sputum specimens from all case-patients and provided them to the Mycobacteriology Unit (a World Health Organization Supranational TB Reference Laboratory) at Vall d'Hebron University Hospital in Barcelona, Spain, for culture and drug-susceptibility testing. Positive cultures were tested by using GenoType MTBDRplus 2.0 (Hain Lifescience $\mathrm{GmbH}$, Nehren, Germany). Isolates identified as Mycobacterium tuberculosis complex (MTBC) underwent drugsusceptibility testing with BD-MGIT-960 SIRE and PZA kits (Becton Dickinson Diagnostic Systems, Sparks, MD, USA). Isolates that were resistant to $\geq 1$ drug were subjected to drug-susceptibility testing for second-line TB drugs by using the BD-MGIT-960 SIRE system.

We performed statistical analysis by using Stata 12 (StataCorp LLC, College Station, TX, USA). We considered a $p$ value $<0.05$ to be statistically significant. We calculated the percentage of patients with resistance patterns to first- and second-line TB drugs on the basis of total number of cases and the total number of MDR TB cases, respectively.

We included 422 cases; 44 were excluded because sputum specimen was not obtained (online Technical Appendix Figure, https://wwwnc.cdc.gov/EID/article/24/3/17-1562Techapp1.pdf). Of these cases, we classified 311 as new and the remaining 111 as retreatment cases. We isolated MTBC in 225 of the new cases. We observed no difference in the distribution of age, sex, or HIV status between casepatients with suspected or confirmed TB disease among the new cases. We isolated MTBC in 83 of the retreatment cases. We found case-patients in whom MTBC was not isolated were more frequently HIV-positive $(14.3 \%$ compared with $4.8 \%$ in whom TB was confirmed; $p=0.09$ ). We observed no difference in sociodemographic characteristics between patients with new and retreatment culture-positive cases (online Technical Appendix Table 1).

Eighteen (8.0\%) of the 225 MTBC isolates from new cases demonstrated multidrug resistance. Other combinations of drug resistance were identified in $40(17.8 \%)$ of new cases. The incidence of primary resistance was as follows: isoniazid, 47 cases $(20.9 \%)$; streptomycin, 25

${ }^{1}$ These authors were co-principal investigators for this article. 
cases $(11.1 \%)$; rifampin, 20 cases $(8.9 \%)$; pyrazinamide, 13 cases, (5.8\%); and ethambutol, 10 cases (4.4\%) (Table 1). No isolates showed extensively drug-resistant TB (online Technical Appendix Table 2).

Among the 47 isoniazid-resistant isolates, $k a t G$ mutations occurred in $26(55.3 \%)$ and inhA mutations in 2 (4.3\%); the remaining 19 isolates $(40.4 \%)$ were classified as susceptible (Table 2). Among the 20 rifampin-resistant isolates, $r p o B$ mutations occurred in $19(95.0 \%)$, and 1 $(5.0 \%)$ was classified as susceptible. Mutations detected included S531L (12 cases, 60.0\%); D516V (4 cases, 20.0\%); and H526Y (2 cases, $10.0 \%$ ) (Table 2).

Fifty-nine $(71.1 \%)$ of the 83 MTBC isolates from retreatment case-patients demonstrated multidrug resistance, and $33.9 \%$ of these case-patients had isolates that were resistant to all first-line drugs. Other combinations of drug resistance were identified in 10 case-patients $(12.0 \%)$ (Table 1). No case-patients had extensively drug-resistant TB (online Technical Appendix Table 2).

Among the 66 isoniazid-resistant isolates, $k a t G$ mutations occurred in $47(71.2 \%)$ and inhA mutations in 4 (6.1\%); the remaining $15(22.7 \%)$ isolates were classified as susceptible (Table 2). Among the 61 rifampin-resistant isolates, $r p o B$ mutations occurred in $58(95.1 \%)$, and the remaining $3(4.9 \%)$ were classified as susceptible. Mutations detected included S531L (37 cases, 60.7\%), D516V (11 cases, 18.5\%), and H526D (3 cases, 3.7\%) (Table 2).

\section{Conclusions}

We found a high prevalence of MDR TB among retreatment $(71.1 \%)$ and new $(8.0 \%)$ cases. These rates are $>4$ times the estimated prevalence of MDR TB for Angola (21\% for retreatment cases, $2.8 \%$ for new cases) (1). The rates we describe represent the highest rates of MDR TB reported in sub-Saharan Africa (2,3); not even South Africa has reported a higher prevalence of MDR TB (4).

Our findings are part of a larger project to reinforce the capacities of the diagnostic laboratory by incorporation of the Xpert MTB/RIF test (Cepheid, Maurens-Scopont, France) (5). At the beginning of the project, none of the 18 provinces in Angola had access to the test; moreover, Nossa Senhora da Paz Hospital is a reference center for the diagnosis and treatment of TB, and these 2 factors might have generated a pull effect in more severe cases. Patients in the study might have largely consisted of TB patients referred because of poor treatment response or availability of second-line treatment, thus overrepresenting patients with resistance patterns, particularly among retreatment patients. This suggestion is supported by the high proportion of retreatment patients in the eligible study population

\begin{tabular}{|c|c|c|c|c|}
\hline \multirow[b]{2}{*}{ Phenotypic drug susceptibility } & \multicolumn{2}{|c|}{ Isolates from new cases, $\mathrm{n}=225$} & \multicolumn{2}{|c|}{ Isolates from retreatment cases, $n=83$} \\
\hline & No. & $\%(95 \mathrm{Cl})$ & No. & $\%(95 \mathrm{Cl})$ \\
\hline Susceptible to all 5 first-line drugs & 167 & $74.2(68.1-79.5)$ & 14 & $16.9(10.3-26.3)$ \\
\hline Resistance to any drug & 58 & $25.8(20.5-31.9)$ & 69 & $83.1(73.7-89.7)$ \\
\hline \multicolumn{5}{|l|}{ Any resistance to the following } \\
\hline INH & 47 & $20.9(16.1-26.7)$ & 66 & $79.5(69.6-86.8)$ \\
\hline RIF & 20 & $8.9(5.8-13.3)$ & 61 & $73.5(63.1-81.8)$ \\
\hline STM & 25 & $11.1(7.6-15.9)$ & 42 & $50.6(40.1-61.1)$ \\
\hline EMB & 10 & $4.4(2.4-8.0)$ & 32 & $38.6(28.8-49.3)$ \\
\hline $\mathrm{PZA}$ & 13 & $5.8(3.4-9.6)$ & 37 & $44.6(34.4-55.3)$ \\
\hline Overall monodrug resistance & 31 & $13.8(9.9-18.9)$ & 7 & $8.4(4.1-16.4)$ \\
\hline INH only & 21 & $9.3(6.2-13.8)$ & 4 & $4.8(1.9-11.7)$ \\
\hline RIF only & 1 & $0.4(0.1-2.5)$ & 2 & $2.4(0.7-8.4)$ \\
\hline STM only & 8 & $3.6(1.8-6.9)$ & 1 & $1.2(0.2-6.5)$ \\
\hline PZA only & 1 & $0.4(0.1-2.5)$ & 0 & $0.0(0.0-4.4) \dagger$ \\
\hline Overall multidrug resistance & 18 & $8.0(5.1-12.3)$ & 59 & $71.1(60.6-79.7)$ \\
\hline INH + RIF & 4 & $1.8(0.7-4.5)$ & 12 & $14.5(8.5-23.6)$ \\
\hline INH + RIF + STM & 2 & $0.9(0.2-3.2)$ & 5 & $6.0(2.6-13.3)$ \\
\hline $\mathrm{INH}+\mathrm{RIF}+\mathrm{EMB}$ & 0 & $0.0(0.0-1.7) \dagger$ & 3 & $3.6(1.2-10.1)$ \\
\hline $\mathrm{INH}+\mathrm{RIF}+\mathrm{PZA}$ & 2 & $0.9(0.2-3.2)$ & 2 & $2.4(0.7-8.4)$ \\
\hline INH + RIF + STM + EMB & 3 & $1.3(0.5-3.8)$ & 4 & $4.8(1.9-11.7)$ \\
\hline INH + RIF + STM + PZA & 1 & $0.4(0.1-2.5)$ & 9 & $10.8(5.8-19.3)$ \\
\hline $\mathrm{INH}+\mathrm{RIF}+\mathrm{EMB}+\mathrm{PZA}$ & 1 & $0.4(0.1-2.5)$ & 4 & $4.8(1.9-11.7)^{\prime}$ \\
\hline $\mathrm{INH}+\mathrm{RIF}+\mathrm{STM}+\mathrm{EMB}+\mathrm{PZA}$ & 5 & $2.2(1.0-5.1)$ & 20 & $24.1(16.2-34.3)$ \\
\hline Overall polydrug resistance & 9 & $4.0(2.1-7.4)$ & 3 & $3.6(1.2-10.1)$ \\
\hline INH + STM & 5 & $2.2(1.0-5.1)$ & 0 & $0.0(0.0-4.4) \dagger$ \\
\hline INH + EMB & 1 & $0.4(0.1-2.5)$ & 0 & $0.0(0.0-4.4) \dagger$ \\
\hline $\mathrm{INH}+\mathrm{PZA}$ & 2 & $0.9(0.2-3.2)$ & 0 & $0.0(0.0-4.4) \dagger$ \\
\hline $\mathrm{INH}+\mathrm{STM}+\mathrm{EMB}$ & 0 & $0.0(0.0-1.7) \dagger$ & 1 & $1.2(0.2-6.5)$ \\
\hline INH + STM + PZA & 0 & $0.0(0.0-1.7) \dagger$ & 2 & $2.4(0.7-8.4)$ \\
\hline RIF + STM + PZA & 1 & $0.4(0.1-2.5)$ & 0 & $0.0(0.0-4.4) \dagger$ \\
\hline
\end{tabular}

*EMB, ethambutol; INH, isoniazid; PZA, pyrazinamide; RIF, rifampin; STM, streptomycin.

†1-sided, $97.5 \% \mathrm{Cl}$. 
Drug Resistance of M. tuberculosis Complex, Angola

Table 2. Distribution of gene mutations associated with INH and RIF resistance, Cubal, Angola, April 2014-July 2015*

\begin{tabular}{|c|c|c|c|c|c|}
\hline \multirow[b]{2}{*}{ Phenotypic resistance } & \multicolumn{3}{|c|}{ GenoType MTBDRplus } & \multirow{2}{*}{$\begin{array}{l}\text { Isolates from new } \\
\text { cases }\end{array}$} & \multirow{2}{*}{$\begin{array}{l}\text { Isolates from } \\
\text { retreatment cases }\end{array}$} \\
\hline & katG & $\operatorname{inh} A$ & $r p o B$ & & \\
\hline \multirow[t]{7}{*}{$\mathrm{INH}, \mathrm{n}=113$} & & & & 47 & 66 \\
\hline & $\Delta \mathrm{wt}, \mathrm{S} 315 \mathrm{~T} 1$ & - & & 23 & 42 \\
\hline & $\Delta \mathrm{wt}$ & - & & 3 & 5 \\
\hline & - & $\Delta \mathrm{wt1}, \mathrm{C} 15 \mathrm{~T}$ & & 2 & 2 \\
\hline & _- & $\Delta w t 1$ & & 0 & 1 \\
\hline & - & C15T & & 0 & 1 \\
\hline & - & - & & 19 & 15 \\
\hline \multirow[t]{12}{*}{ RIF, $n=81$} & & & & 20 & 61 \\
\hline & & & - & 1 & 3 \\
\hline & & & $\Delta w t 2$ & 0 & 2 \\
\hline & & & $\Delta \mathrm{wt2,3,4,} \mathrm{D516V}$ & 1 & 8 \\
\hline & & & $\Delta \mathrm{wt3}, 4, \mathrm{D} 516 \mathrm{~V}$ & 3 & 3 \\
\hline & & & $\Delta \mathrm{wt} 4,5$ & 0 & 1 \\
\hline & & & $\Delta \mathrm{wt} 7$ & 0 & 1 \\
\hline & & & $\Delta \mathrm{wt} 7, \mathrm{H} 526 \mathrm{Y}$ & 2 & 0 \\
\hline & & & $\Delta \mathrm{wt} 7, \mathrm{H} 526 \mathrm{D}$ & 0 & 2 \\
\hline & & & $\Delta w t 7,8, H 526 D$ & 0 & 1 \\
\hline & & & $\Delta w t 8$ & 1 & 3 \\
\hline & & & $\Delta w t 8$, S531L & 12 & 37 \\
\hline
\end{tabular}

(26.3\% where the expected population proportion would be $10 \%-15 \%)$ and the extremely high prevalence of MDR TB in this group (in particular compared with new patients). Also, for new patients, such selection bias might have occurred, for example, because TB patients who were contacts of known or suspected MDR TB patients were preferentially referred to this facility.

Regarding associated mutations, previous studies have shown that $\approx 95 \%$ of resistance mutations to rifampin are associated with the rроB gene mutations, which cluster mainly in the region of codon 507-533. In our study, the distribution of gene mutations among rifampin-resistant isolates was $60.4 \%$ Ser531Leu, 18.5\% Asp516Val, 3.7\% His526Asp, and $2.5 \%$ His $526 \mathrm{Tyr}$; in $9.9 \%$ of cases, the mutation was detected by the absence of the wild-type hybridization signal. This distribution is different from that previously reported, reflecting different distribution of gene mutations associated with rifampin resistance in different geographic locations (6) or different levels of maturation of the MDR TB epidemic. In areas with high MDR TB prevalence and a high proportion of MDR TB cases attributed to transmission, mutations that confer resistance without loss of reproductive fitness will be selected out $(7,8)$.

Whereas $40 \%-95 \%$ of isoniazid-resistant isolates are defined as having high-level drug resistance because of kat G gene mutations, $75 \%-90 \%$ of which are recognized as mutations in the 315 codon of the kat $G$ gene, in our study, $57.5 \%$ of isoniazid-resistant isolates were associated with mutations in the 315 codon of the $k a t G$ gene. Approximately $8 \%-43 \%$ of isoniazid-resistant isolates are defined as having low-level drug resistance because of mutations in the promoter region of inhA. In our study, this proportion was $5.3 \%$. Furthermore, $10 \%-25 \%$ of isoniazid-resistant isolates are thought to have mutations outside the $k a t G$ and inhA loci (9-11).
This work was supported by Probitas Foundation. Thanks to the financial support received from Probitas Foundation, it was possible not only to purchase the equipment and reagents to launch the study but to strengthen the capacity of the laboratory and local staff. The funder had no role in the study design, data collection and analysis, decision to publish, or preparation of the manuscript.

\section{About the Author}

Ms. Rando-Segura is a predoctoral fellow in the Mycobacteriology Unit at the Hospital Universitari Vall d'Hebron in Barcelona, Spain. Her primary research interest is the genetic determinants responsible for antibiotic resistance.

\section{References}

1. World Health Organization. Global tuberculosis report 2016. Geneva: The Organization; 2016.

2. Menzies HJ, Moalosi G, Anisimova V, Gammino V, Sentle C, Bachhuber MA, et al. Increase in anti-tuberculosis drug resistance in Botswana: results from the fourth National Drug Resistance Survey. Int J Tuberc Lung Dis. 2014;18:1026-33. http://dx.doi.org/10.5588/ijtld.13.0749

3. Kapata N, Mbulo G, Cobelens F, de Haas P, Schaap A, Mwamba P, et al. The Second Zambian National Tuberculosis Drug Resistance survey - a comparison of conventional and molecular methods. Trop Med Int Health. 2015;20:1492-500. http://dx.doi.org/10.1111/ tmi. 12581

4. National Institute for Communicable Diseases. South African Tuberculosis Drug Resistance Survey 2012-12. Johannesburg (South Africa): The Institute; 2016.

5. Fundación PROBITAS. Annual report 2013 [cited 2016 Sep 1]. http://www.fundacionprobitas.org/documents/14775454/ 14952167/annual+report+2013+\%28english\%29/ 2594c68b-6489-4044-8f48-3bbce85490c9

6. Zhang L, Ye Y, Duo L, Wang T, Song X, Lu X, et al. Application of genotype MTBDRplus in rapid detection of the Mycobacterium tuberculosis complex as well as its resistance to isoniazid and rifampin in a high volume laboratory in Southern China. 
Mol Biol Rep. 2011;38:2185-92. http://dx.doi.org/10.1007/ s11033-010-0347-0

7. Cohen T, Becerra MC, Murray MB. Isoniazid resistance and the future of drug-resistant tuberculosis. Microb Drug Resist. 2004;10:280-5. http://dx.doi.org/10.1089/mdr.2004.10.280

8. Knight GM, Colijn C, Shrestha S, Fofana M, Cobelens F, White RG, et al. The distribution of fitness costs of resistanceconferring mutations is a key determinant for the future burden of drug-resistant tuberculosis: a model-based analysis. Clin Infect Dis. 2015;61(Suppl 3):S147-54. http://dx.doi.org/10.1093/cid/civ579

9. Vilchèze C, Jacobs WR Jr. The mechanism of isoniazid killing: clarity through the scope of genetics. Annu Rev Microbiol. 2007;61:35-50. http://dx.doi.org/10.1146/annurev.micro.61. 111606.122346
10. Riccardi G, Pasca MR, Buroni S. Mycobacterium tuberculosis: drug resistance and future perspectives. Future Microbiol. 2009;4:597-614. http://dx.doi.org/10.2217/fmb.09.20

11. Hazbón MH, Brimacombe M, Bobadilla del Valle M, Cavatore M, Guerrero MI, Varma-Basil M, et al. Population genetics study of isoniazid resistance mutations and evolution of multidrug-resistant Mycobacterium tuberculosis. Antimicrob Agents Chemother. 2006;50:2640-9. http://dx.doi.org/10.1128/AAC.00112-06

Address for correspondence: María Teresa Tórtola,

Microbiology Department, Vall d'Hebron University Hospital, Passeig Vall d'Hebron 119-129, 08035, Barcelona, Spain; email: ttortola@vhebron.net

\section{March 2013: Tuberculosis}

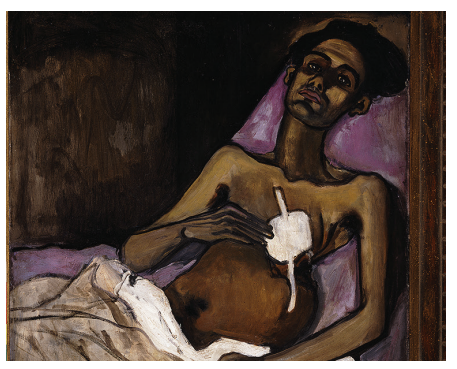

- Measles Elimination Efforts and 2008-2011 Outbreak, France

- Nontuberculous Mycobacterial Infection after Fractionated $\mathrm{CO}_{2}$ Laser Resurfacing

- Human Leptospirosis Trends, the Netherlands, 1925-2008

- Parallels in Amphibian and Bat Declines from Pathogenic Fungi

- Increasing Pneumocystis Pneumonia, England, UK, 2000-2010

- Pulmonary Nontuberculous Mycobacterial Disease, Brazil, 1993-2011

- Tuberculosis and HIV Co-infection, California, 1993-2008

- Attribution of Foodborne Illnesses, Hospitalizations, and Deaths to Food Commodities by Using Outbreak Data, United States, 1998-2008

- Treatment Outcomes for Extensively Drug-Resistant Tuberculosis and HIV Co-infection

- Foodborne Disease Prevention and Broiler Chickens with Reduced Campylobacter Infection

- Lack of Norovirus Replication and Histo-Blood Group Antigen Expression in 3-Dimensional Intestinal Epithelial Cells

- Effects of Vaccine Program against Pandemic Influenza A(H1N1) Virus, United States, 2009-2010

- Emergence and Spread of Extensively and Totally Drug-Resistant Tuberculosis, South Africa
- Human

Betacoronavirus 2c EMC/2012-related Viruses in Bats, Ghana and Europe

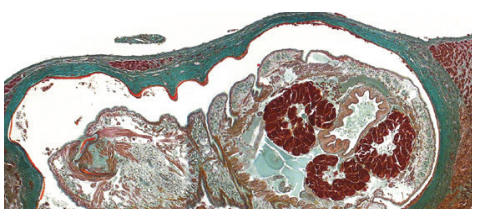

- Mycobacterial Lineages Causing Pulmonary and Extrapulmonary Tuberculosis, Ethiopia

- Swine Influenza in Sri Lanka

- Unexpected Increase of Alveolar Echincoccosis, Austria, 2011

- Vibrio cholerae Non-01, Non-0139 Serogroups and Cholera-like Diarrhea, Kolkata, India

- Hepatitis E Virus Mixed Infection in Immunocompetent Patient

- Virulence of Pertactin-Negative Bordetella pertussis Isolates from Infants, France

- Multidrug-Resistant Tuberculosis, Somalia, 2010-2011

- Swine Influenza in Sri Lanka Tuberculosis Outbreak in a Primary School, Milan, Italy

- Lymphogranuloma Venereum in Men Screened for Pharyngeal and Rectal Infection, Germany

- Prioritizing Tuberculosis Clusters by Genotype for Public Health Action, Washington
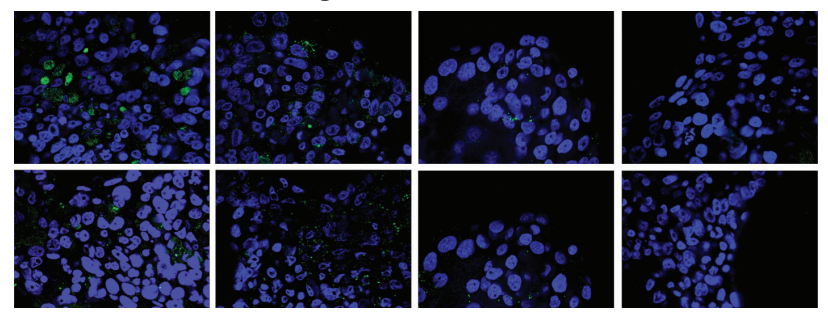

\section{EMERGING}

INFECTIOUS DISEASES https://wwwnc.cdc.gov/eid/articles/issue/19/3/table-of-contents 